\title{
Evidence that Rodents Are a Reservoir of Hepatitis E Virus for Humans in Nepal
}

\author{
Junkun He, ${ }^{1}$ Bruce L. Innis, ${ }^{1} \dagger$ Mrigendra P. Shrestha, ${ }^{2}$ Edward T. Clayson, ${ }^{3} \ddagger$ Robert M. Scott ${ }^{2}$ \\ Kenneth J. Linthicum, ${ }^{3} \S$ Guy G. Musser, ${ }^{4}$ Scott C. Gigliotti, ${ }^{3}$ Leonard N. Binn, ${ }^{1}$ \\ Robert A. Kuschner, ${ }^{1}$ and David W. Vaughn ${ }^{1 *}$ \\ Walter Reed Army Institute of Research, Silver Spring, Maryland ${ }^{1}$; Walter Reed Army Institute \\ of Research/Armed Forces Research Institute of Medical Sciences Research Unit-Nepal, Kathmandu, \\ Nepal $^{2}$; Armed Forces Research Institute of Medical Sciences, Bangkok, Thailand ${ }^{3}$; \\ and American Museum of Natural History, New York, New York ${ }^{4}$
}

Received 21 May 2002/Returned for modification 7 August 2002/Accepted 30 August 2002

\begin{abstract}
Hepatitis E virus (HEV) is an important cause of enterically transmitted hepatitis in developing countries. Sporadic autochthonous cases of hepatitis $E$ have been reported recently in the United States and other industrialized countries. The source of HEV infection in these cases is unknown; zoonotic transmission has been suggested. Antibodies to HEV have been detected in many animals in areas where HEV is endemic and in domestic swine and rats in the United States. There is evidence supporting HEV transmission between swine and humans. Nevertheless, HEV has not been detected in wild rodents. We tested murid rodents and house shrews trapped in Nepal's Kathmandu Valley, where hepatitis E is hyperendemic, for HEV infection. The most commonly trapped species was Rattus rattus brunneusculus. Serum samples from 675 animals were tested for immunoglobulin G against HEV by enzyme-linked immunosorbent assay; $78(12 \%)$ were positive, indicating acute or past infection. Antibody prevalence was higher among $R$. rattus brunneusculus and Bandicota bengalensis than in Suncus murinus. Forty-four specimens from $\mathbf{7 8}$ antibody-positive animals had sufficient residual volume for detection of HEV RNA (viremia) by reverse transcription-PCR. PCR amplification detected four animals (9\%; three were $R$. rattus brunneusculus and one was $B$. bengalensis) with viremia. Phylogenetic analysis of the four genome sequences $(405 \mathrm{bp}$ in the capsid gene) recovered showed that they were identical, most closely related to two human isolates from Nepal (95 and $96 \%$ nucleotide homology, respectively), and distinct from HEV sequences isolated elsewhere. These data prove that certain peridomestic rodents acquire HEV in the wild and suggest that cross-species transmission occurs, with rodents serving as a virus reservoir for humans.
\end{abstract}

Hepatitis E virus (HEV) is the most important cause of acute hepatitis in many developing countries of Asia, the Middle East, and Africa as well as in Mexico (29). In industrialized countries, autochthonous hepatitis E was thought to be absent. Yet recently, a few autochthonous hepatitis E cases from the United States and other industrialized countries have been reported $(12,13,18,22,24,31,32,39)$.

HEV transmission is thought to occur primarily by the fecaloral route; water-borne epidemics are characteristic $(1,28,29)$. Therefore, the occurrence of isolated hepatitis E cases can be explained only by silent transmission of HEV among human or animal case contacts.

The occurrence of autochthonous hepatitis E in industrialized countries has focused renewed attention on the question of whether hepatitis E is a zoonosis (29; M. Favorov, O. Nazarova, and H. S. Margolis, presented at the Second Interna-

\footnotetext{
* Corresponding author. Present address: Military Infectious Diseases Research Program, U.S. Army Medical Research and Materiel Command, 504 Scott St., Fort Detrick, MD 21702-5012. Phone: (301) 619-7882. Fax: (301) 619-2416. E-mail: david.vaughn@det.amedd.army mil.

$\dagger$ Present address: Clinical Research and Development and Medical Affairs, Vaccines, GlaxoSmithKline, Collegeville, PA 19426.

$\$$ Present address: Joint Program Office for Biological Defense, Falls Church, VA 22041-3203.

$\S$ Present address: Vector-Borne Disease Section, Southern Region, California Department of Health Services, Ontario, CA 91764.
}

tional Conference on Emerging Zoonoses, Strasbourg, France, 5 to 9 November 1998). Antibodies to HEV have been found in cows, sheep, goats, chickens, water buffaloes, swine, wild rats, mice, and monkeys from areas where hepatitis $E$ is endemic and in domestic swine and rats in the United States (3, 9, 10, 20, 21, 26, 37). Successful transmission of human HEV isolates to monkeys, swine, rats, and sheep in the former Soviet Union and in Asia has been reported (2, 5, 7, 23, 35). Interestingly, HEV recovered from a patient in the United States was found to be closely related to swine HEV (25), suggesting that this patient's infection was zoonotic.

The aim of this study was to look for additional evidence that rodents also might serve as an animal reservoir of HEV. We examined 675 wild rodents and house shrews trapped in Nepal's Kathmandu Valley, where hepatitis E is hyperendemic. A serum specimen from each animal was tested for immunoglobulin $\mathrm{G}(\mathrm{IgG})$ to $\mathrm{HEV}$; positive specimens were further tested for the HEV genome, and amplified genome sequences were characterized phylogenetically. Here we present evidence that $\mathrm{HEV}$ is transmitted between murine rodents and humans in Kathmandu, and we suggest that murine rodents spread hepatitis $\mathrm{E}$ to humans elsewhere.

\section{MATERIALS AND METHODS}

Rodent collection. Rodents of the subfamily Murinae as defined by Carleton and Musser (8) and house shrews (Suncus murinus; family Soricidae) were trapped from 1994 to 1996 at various locations in the following cities within the 
TABLE 1. Rodents and shrews examined and results of testing for IgG to HEV

\begin{tabular}{|c|c|c|c|c|c|}
\hline Species & $\begin{array}{l}\text { No. of animals } \\
\text { trapped }\end{array}$ & $\begin{array}{l}\text { No. with antibody } \\
\text { levels of } \geq 5 \\
\mathrm{moU} / \mathrm{ml}\end{array}$ & $\begin{array}{l}\text { Antibody prevalence } a \\
\qquad(95 \% \mathrm{CI})^{b}\end{array}$ & $\begin{array}{l}\mathrm{GMC}^{c} \text { of positive } \\
\text { specimens } \\
(\mathrm{moU} / \mathrm{ml})\end{array}$ & $\begin{array}{c}\text { Min-max }{ }^{d} \text { values } \\
\text { of positive } \\
\text { specimens } \\
(\mathrm{moU} / \mathrm{ml})\end{array}$ \\
\hline Rattus rattus brunneusculus & 350 & 45 & $13(9-17)$ & 48 & $6-107$ \\
\hline Bandicota bengalensis & 39 & 8 & $21(9-36)$ & 63 & 49-92 \\
\hline Suncus murinus & 108 & 2 & $2(0.2-6)$ & 50 & $35-71$ \\
\hline Mus musculus castaneus & 3 & 0 & 0 & 0 & 0 \\
\hline Unidentified murine rodents & 174 & 23 & $13(8-19)$ & 33 & $5-98$ \\
\hline Total & 675 & 78 & $12(9-14)$ & 45 & $5-107$ \\
\hline
\end{tabular}

${ }^{a}$ Expressed as a percentage.

b $95 \%$ CI, exact $95 \%$ confidence interval for the binomial distribution.

${ }^{c} \mathrm{GMC}$, geometric mean concentration.

${ }^{d}$ Min, minimum; max, maximum.

Kathmandu Valley: Kathmandu, Bhaktapur, and Lalitpur. Animals were sacrificed, and serum specimens were kept at $-80^{\circ} \mathrm{C}$. Rodents and shrews were initially identified by species at the Armed Forces Research Institute of Medical Sciences, Bangkok, Thailand. Subsequently, representative rodent and shrew bodies were sent to the American Museum of Natural History, New York, N.Y., for further identification.

EIA. IgG to HEV capsid protein was detected as previously described for mouse specimens (15) with the following modifications. To increase the sensitivity of the test for diverse rodent species for which no antiserum was commercially available, the secondary antibody was a 1:1 mixture of peroxidase-labeled goat anti-mouse IgG and anti-rat IgG. For the same reason, we used a 1:1 ratio of mouse and rat HEV hyperimmune sera to make a standard curve for antibody quantitation. The negative control was a 1:1 mixture of rat and mouse preimmune sera. In this enzyme immunoassay (EIA), IgG to HEV can be quantitated down to 0.1 mouse unit $(\mathrm{moU}) / \mathrm{ml})$. The cutoff was conservatively set to define a positive test as $\geq 5 \mathrm{moU}$ of anti-HEV IgG/ml. As the optical density (OD) of the negative control is consistently below $0.01 \mathrm{OD}$ unit, $5 \mathrm{moU}$ is approximately equivalent to $0.6 \mathrm{OD}$ unit. The sensitivity of this assay for antibody to $\mathrm{HEV}$ in $S$. murinus is unknown.

RT-PCR. Initial testing for HEV viremia was performed by using 44 seropositive specimens with a sufficient residual sample volume of 30 to $50 \mu \mathrm{l}$ (group 1). Additional testing for HEV viremia was performed by using the remaining 34 seropositive specimens with a residual volume of $<10 \mu$ l (group 2). Before RNA was extracted from a serum specimen by use of TRIzol reagent (Life Technologies, Rockville, Md.), the specimen volume was increased to $100 \mu$ l by addition of fetal bovine serum. One milliliter of TRIzol reagent was added, the sample was vortexed vigorously, and $200 \mu \mathrm{l}$ of chloroform was added immediately after vortexing. After centrifugation at $12,000 \mathrm{rpm}(11,750 \times \mathrm{g})$ for $15 \mathrm{~min}$ at $10^{\circ} \mathrm{C}, 0.6$ $\mathrm{ml}$ of supernatant was transferred to another tube and $0.6 \mathrm{ml}$ of isopropanol was added to the sample. The suspension was vortexed vigorously, kept at room temperature for $5 \mathrm{~min}$, and then centrifuged for $10 \mathrm{~min}$ at $11,750 \times \mathrm{g}$ and $20^{\circ} \mathrm{C}$. After centrifugation, the supernatant was discarded, the RNA pellet was washed with $1 \mathrm{ml}$ of $75 \%$ ethanol and vortexed vigorously, and the sample was spun again at $11,750 \times g$ for $4 \mathrm{~min}$ at $4^{\circ} \mathrm{C}$. After this centrifugation, the supernatant was poured out, and the RNA pellet was dried and then dissolved in $85 \mu \mathrm{l}$ of reaction solution (containing $1 \times$ PCR buffer, $2.5 \mathrm{mM}$ deoxynucleoside triphosphates, and $50 \mathrm{pmol}$ of the antisense primer SR1). Reverse transcription-PCR (RT-PCR) was performed as described previously (16). The sequences of primer sets were derived from ORF-2 of HEV Burma, which shares 95\% nucleotide sequence identity with a previously characterized human HEV strain from Nepal (14). The primers used for the first-round PCR were SF1 (sense) (nucleotides 6578 to 6596; 5'-GCCGAGTATGACCAGTCCA-3') and SR1 (antisense) (nucleotides 7127 to $7107 ; 5^{\prime}$-ACAACTCCCGAGTTTTACCC-3'). The primers for the second-round PCR (nested PCR) were SF2 (sense) (nucleotides 6650 to 6668; 5'-AATGTTGCGACCGGCGCGC-3') and SR2 (antisense) (nucleotides 7098 to $7078 ; 5^{\prime}$-TAAGGCGCTGAAGCTCAGC-3'). GenBank database searching indicated that there were two HaeIII restriction enzyme sites and one KpnI site in this fragment in most HEV strains, especially in the Asian-African genotype. Amplified products were digested with HaeIII and KpnI restriction enzymes and analyzed by $1 \%$ agarose gel electrophoresis.

DNA sequence analysis. To confirm the positive RT-PCR results, DNA sequencing was carried out on each 448-bp nested PCR product. Primer Designer 4, version 4.1 (Scientific \& Educational Software, Durham, N.C.), was used to design primers for sequencing. Primers used for sequencing were SF3 (sense) (nucleotides 6722 to 6742 ; 5'-CTCTCCACCATCCAGCAGTA-3') of HEV strain Burma and SR3 (antisense) (nucleotides 7091 to 7071; 5'-GCTGAAGC TCAGCGACAGTA-3'). PCR products were purified by use of the QIAquick PCR purification and gel extraction kits (Qiagen, Santa Clarita, Calif.). The resulting DNA was sequenced in both directions on an Applied Biosystems (Foster City, Calif.) model 377 sequencing system by using the recommended Tag Dye-Deoxy Terminator Cycle Sequencing kit (Perkin-Elmer Applied Biosystems, Warrington, United Kingdom).

Phylogenetic analysis. Sequence database searching, comparison, and analysis were performed with the Align Plus 4, version 4.0, software program for Windows (Scientific \& Educational Software), the BLASTn program (BLAST, version 2.0; National Center for Biotechnology Information [NCBI], Bethesda, Md.), and a sequence database searching program (BioNavigator, Sunnyvale, Calif.).

The consensus sequences for the Nepalese rodent HEV obtained in this study were compared to sequences of $14 \mathrm{HEV}$ strains isolated from different geographic areas (Asia, Africa, and America) which are available from GenBank. The multiway alignment procedure consisted of exhaustive pairwise global alignments of $18 \mathrm{HEV}$ sequences, progressive assembly of alignments, and construction of an evolutionary tree by using neighbor-joining (NJ) phylogeny. A dendrogram which suggests the pattern of relatedness of all the sequences aligned was constructed with a distance-based tree-building method using the NJ algorithm. The amount of dissimilarity (the distance) between two aligned sequences was used to produce the tree. The graphic output of the phylogenetic trees was created with Align Plus 4, version 4.0, for Windows. The GenBank accession numbers for 14 of $18 \mathrm{HEV}$ sequences used for phylogenetic studies are listed in Table 3; the others were Nepalese rodent HEV (see below) and HEV strains China-A, -B, and -C, with GenBank accession numbers D11092, L25547, and L25595, respectively $(4,6,38)$.

Nucleotide sequence accession number. The sequences of the rodent HEV reported in this paper have been deposited in GenBank (NCBI) and assigned accession number AF396860.

\section{RESULTS}

Of 675 animals trapped, the majority $(74 \%)$ were trapped in urban neighborhoods of Kathmandu. Most (89\%) were caught in 1996. Five hundred one animals $(74 \%)$ were identified by species; the predominant species was Rattus rattus brunneusculus (Table 1).

Most animals lacked IgG to HEV, but 78 (12\%) of the 675 had $\geq 5 \mathrm{moU}$ of antibody $/ \mathrm{ml}$. Antibody levels among seropositive animals (Fig. 1) were distributed far above the assay cutoff point, with a cluster of positive values around $50 \mathrm{moU} / \mathrm{ml}$, 10 -fold higher than the cutoff point. Serological results by species are summarized in Table 1. Geometric mean antibody concentrations for seropositive animals appeared similar for all species, including those with no identification (Table 1). This 


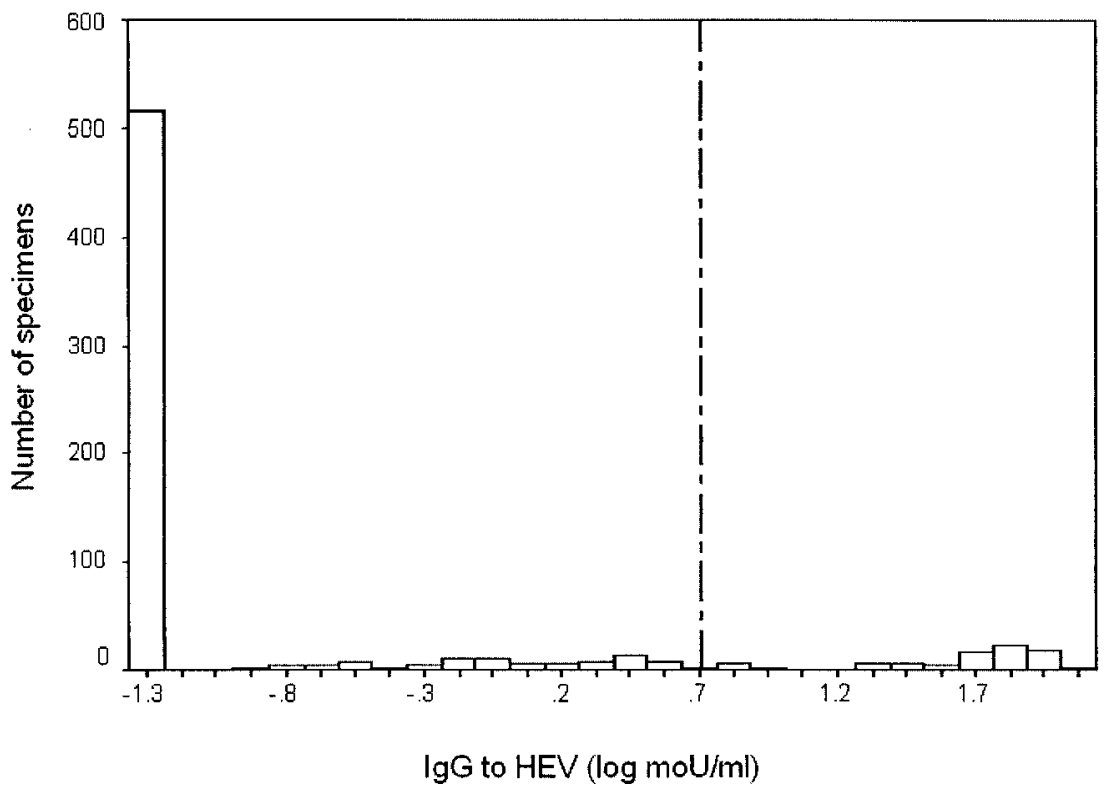

FIG. 1. Histogram of EIA results $(n=675)$ for $\mathrm{IgG}$ to $\mathrm{HEV}$, quantitated as $\log$ mouse units per milliliter. Values of $\geq 5 \mathrm{moU} / \mathrm{ml}$ were considered positive.

suggests that the sensitivity of the assay for Suncus immunoglobulin was acceptable despite use of a secondary label developed for Rattus and Mus. Moreover, the similarity of results among all animals and Rattus suggests that many unidentified animals were Rattus. Despite similar antibody levels among infected animals, antibody prevalence was higher for Rattus and Bandicota than for Suncus. Too few Mus animals were collected for estimation of antibody prevalence.

The prevalences of antibodies to HEV among Rattus and Bandicota animals trapped in the three cities were similar. In four Katmandu neighborhoods where at least 18 animals of these species were trapped in 1996, antibody prevalences were also similar (Fig. 2). These data suggest that rodent infections were diffuse rather than focal.

Seventy eight seropositive specimens were tested for HEV viremia by RT-PCR. Of 44 serum specimens in group 1, with sample volumes that were optimal for a sensitive assay, the HEV genome was detected in 4 (see Table 2 for details). The HEV genome was not detected in any of the 34 serum specimens in group 2, with sample volumes that were suboptimal for the assay. The length of amplified fragments, $448 \mathrm{bp}$, was as expected for HEV. After restriction enzyme digestion of the fragments with HaeIII and KpnI, the digestion pattern of fragments was as expected (data not shown). The overall prevalence of viremia was $9 \%$. The level of viremia was low to moderate; in two of four cases it was detected without nested PCR.

To confirm that the nucleic acid amplified from rodent serum samples came from $\mathrm{HEV}$, PCR fragments were sequenced. The sequences of all four isolates were identical. A 405-nucleotide fragment from the $3^{\prime}$ end of the capsid gene was used to search for related virus sequences in GenBank (NCBI). Sequence alignments confirmed that the DNA sequence amplified from the rodents was an HEV sequence and that it shared 95 to $96 \%$ nucleotide sequence identity and $98 \%$ amino acid sequence identity with two human HEV strains recovered from Nepalese hepatitis E patients in 1987 and 1994 (14). On the other hand, the rodent HEV sequence had less homology with other human or swine HEV isolates (Table 3).

All HEV isolates were from animals trapped in Kathmandu. Each animal had a marked elevation of IgG to HEV, further confirming that the viremia detections were authentic and indicating that in some rodents, virus and antibody can circulate simultaneously in the blood. The date of virus detection for

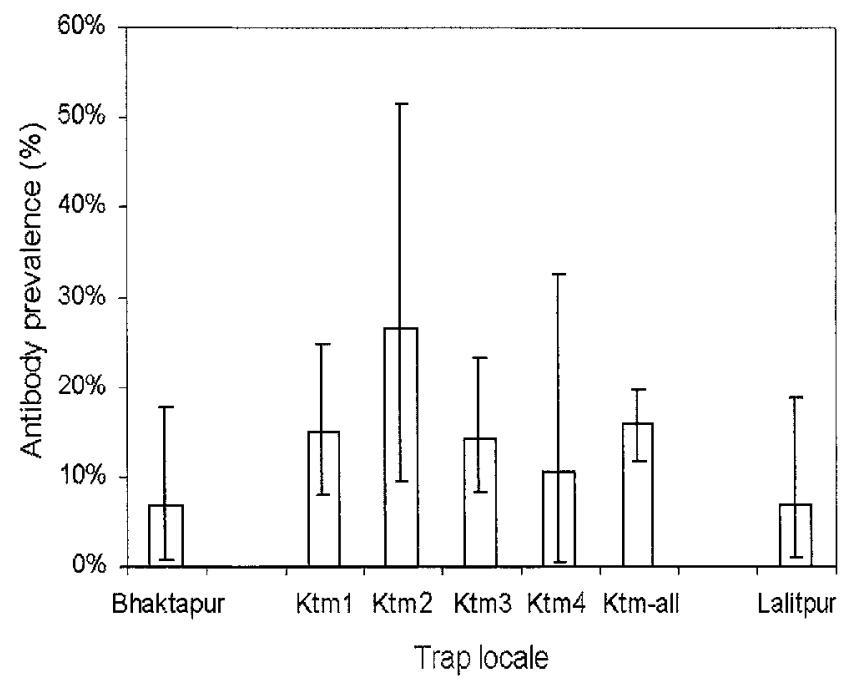

FIG. 2. Prevalence of IgG to HEV among Rattus and Bandicota in the cities of Bhaktapur, Kathmandu, and Lalitpur. Kathmandu results are shown for the whole city (Ktm-all) and for four neighborhoods where more than 18 animals were trapped (Ktm1, Kalmati; Ktm2, Lagan Tole; Ktm3, Sabalbahal; Ktm4, Teku). Error bars, 95\% confidence intervals. 
TABLE 2. Characterization of rodents with HEV viremia

\begin{tabular}{|c|c|c|c|c|c|}
\hline $\begin{array}{l}\text { HEV } \\
\text { isolate no. }\end{array}$ & Rodent species & Date trapped ${ }^{a}$ & City, neighborhood where trapped & $\begin{array}{l}\text { Concn of IgG to } \\
\mathrm{HEV}(\mathrm{moU} / \mathrm{ml})\end{array}$ & $\begin{array}{c}\text { Viremia } \\
\text { quantitation }\end{array}$ \\
\hline 1 & Rattus rattus brunneusculus & 7 Apr. 96 & Kathmandu, unspecified & 56 & $3+$ \\
\hline 2 & Rattus rattus brunneusculus & 15 Sept. 96 & Kathmandu, Sabalbahal & 59 & $3+$ \\
\hline 3 & Rattus rattus brunneusculus & 5 Mar. 96 & Kathmandu, Bhotebahal & 50 & $2+$ \\
\hline 4 & Bandicota bengalensis & 25 July 96 & Kathmandu, Sabalbahal & 49 & $2+$ \\
\hline
\end{tabular}

a 96,1996

${ }^{b} 1+$, weakly visible band after nested PCR; $2+$, strong band after nested PCR; $3+$, weakly visible band after first-round PCR; $4+$, strong band after first-round PCR.

these animals is important because hepatitis E transmission among humans is seasonal in the Kathmandu Valley. Human HEV transmission is presumed to accelerate from very low levels in May to June to levels at least fivefold higher in June to July, when illnesses become overt and hospital case notifications increase following an incubation period of approximately 1 month. Rodent isolates 1 and 2 were recovered from animals trapped on 7 April and 15 March 1996, at least several weeks before epidemic human transmission of HEV was likely to have begun in Kathmandu, based on 1996 case notifications (M. P. Shrestha and R. M. Scott, unpublished data). Rodent isolates 3 and 4 were recovered from animals trapped near the peak of the human epidemic.

A phylogenetic tree was constructed for the Nepalese rodent HEV and 17 other HEV strains (based on the 405-nucleotide capsid gene fragment). HEV sequences are divided into three genotypes as previously described (33): an Asian-African genotype (I), a U.S. genotype (II), and a Mexican genotype (III). Our results show that the Nepalese rodent HEV isolates and two Nepalese human HEV isolates compose a single cluster within the Nepal-India subgenotype of the Asian-African genotype (Fig. 3), implying that these three viruses have a recent common ancestor.

\section{DISCUSSION}

Previously, antibodies to HEV were detected in rodents in the Central Asian regions of the former Soviet Union, where hepatitis $\mathrm{E}$ is endemic, and in the United States, where hepatitis $\mathrm{E}$ is not endemic $(20,21,26)$. These observations suggested that rodents were infected by HEV; nevertheless, the possibility remained that those antibodies were elicited by a virus related to but distinct from HEV. Detection of virus-like particles morphologically and antigenically consistent with HEV, by immune electron microscopy of serum samples from wild rats and mice trapped near the site of a hepatitis E outbreak in Kirgizia (21), did not refute this possibility, particularly because subsequent studies failed to detect $\mathrm{HEV}$ in rodents by using PCR primers designed to amplify all known HEV strains $(20,26)$. Our identification of the HEV genome in rodent serum is the first unconditional proof that HEV naturally infects some wild rodents.

By phylogenetic analysis using a broad cross-section of HEV isolates, the Nepalese rodent HEV isolates are most closely related to $\mathrm{HEV}$ recovered from hepatitis $\mathrm{E}$ patients in the Kathmandu Valley who were infected in 1987 and 1994. These rodent and human viruses have capsid gene sequences with 95 to $96 \%$ nucleotide homology and $98 \%$ amino acid homology. Moreover, a previous phylogenetic analysis based on capsid gene sequences found that human HEV isolates from the Kathmandu Valley collected between 1991 and 1995 were indistinguishable (14). This means that the HEV isolates derived from rodents in 1996 could have shared a common ancestor with human strains isolated between 1987 and 1995 by means of cross-species transmission. As HEV is excreted in feces, and fecally contaminated water has been implicated in human outbreaks, one can speculate that excreta from infected rodents also can contaminate water (or foodstuffs) with the virus, providing a vehicle for enteric transmission to other susceptible rodents, humans, or other species such as swine.

The 13 to $21 \%$ prevalence of antibody to HEV among Rattus

TABLE 3. DNA sequence homology between the Nepalese rodent HEV and other HEV isolates used for phylogenetic analysis

\begin{tabular}{|c|c|c|c|c|c|}
\hline Isolate $^{a}$ & GenBank accession no. & Source & $\begin{array}{c}\text { Nucleotide } \\
\text { identity (\%) }\end{array}$ & $\begin{array}{l}\text { Amino acid } \\
\text { identity }(\%)\end{array}$ & Reference \\
\hline 87-Nepal & AF020495 & Human & 96 & 98 & 14 \\
\hline 94-Nepal & AF020497 & Human & 95 & 98 & 14 \\
\hline 90-India & U22532 & Human & 94 & 96 & 27 \\
\hline 87-China-D & D11093 & Human & 93 & 97 & Unpublished \\
\hline 92-Fulminant (India) & X98292 & Human & 93 & 96 & 30 \\
\hline 87-Pakistan-Sar & M80581 & Human & 92 & 96 & 34 \\
\hline 80-Algeria & U40046 & Human & 89 & 97 & 36 \\
\hline 84-Chad & U62121 & Human & 88 & 97 & 36 \\
\hline 94-Egypt & AF051352 & Human & 89 & 97 & 33 \\
\hline 93-Egypt & AF051351 & Human & 87 & 97 & 33 \\
\hline 83-Namibia & AF105021 & Human & 88 & 98 & 17 \\
\hline 96-USA & AF082843 & Swine & 80 & 91 & 25 \\
\hline 95-USA & AF060669 & Human & 79 & 91 & 31 \\
\hline 87-Mexico & M74506 & Human & 77 & 88 & 19 \\
\hline
\end{tabular}

${ }^{a}$ Numeral in each isolate designation indicates year of isolation. 


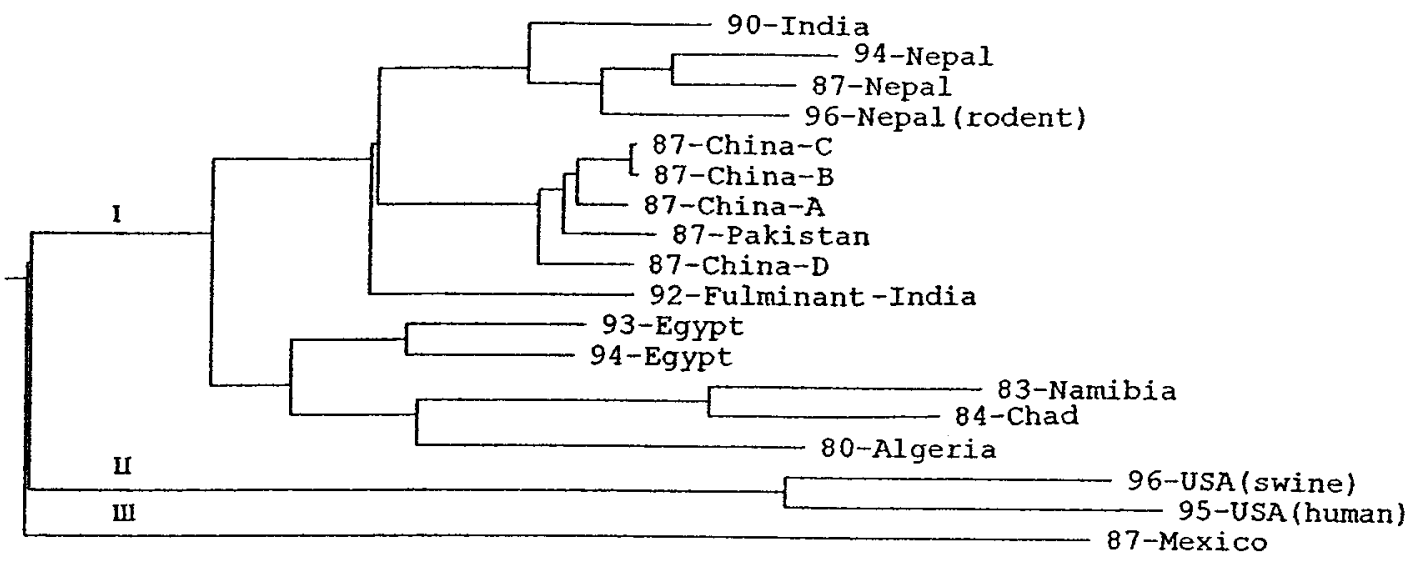

$\overline{0.05}$

FIG. 3. Phylogenetic analysis, using a 405-bp sequence from the capsid gene, of Nepalese rodent HEV and 17 other HEV isolates from around the world. The tree was generated by a distance-based method using the NJ algorithm. The scale bar represents the percentage of dissimilarity (distance) between two aligned sequences.

and Bandicota animals examined suggests that there is extensive transmission of HEV in these species. Antibody prevalence was only $2 \%$ in Suncus animals, suggesting that they are less susceptible or less exposed. We believe that the detection of moderately high levels of HEV IgG in two Suncus animals suggests that low EIA sensitivity is an insufficient explanation for low antibody prevalence in this species. The concurrent detection of HEV and anti-HEV antibodies in $9 \%$ of doubletested rodent specimens in group 1 adds weight to the specificity of all serologic evidence in this study.

The concurrent detection of HEV and moderate levels of anti-HEV IgG in some rodents also suggests that viremia may persist in these animals for some time after the antibody appears in serum. In humans, serum viremia and fecal shedding can persist for weeks even though a specific antibody response has evolved (11). Prolonged fecal shedding during rodent infections obviously would contribute to their vectorial capacity. Moreover, since rodents bite one another, prolonged viremia could facilitate percutaneous transmission of HEV.

Rattus and Bandicota animals that had sustained HEV infection were found in every adequately sampled neighborhood of Kathmandu, the largest city in the Kathmandu Valley. Antibody prevalences in Kathmandu City and the two adjoining urban centers, Bhaktapur and Lalitpur, suggested that transmission was geographically diffuse. Importantly, although two infected animals were trapped during the peak of the human HEV epidemic (July and September), the other two were trapped weeks before the human epidemic, in March and April. The detection of actively infected animals before the human epidemic is consistent with the hypothesis that rodents serve as an animal reservoir and amplify the virus in the environment to create conditions suited for human transmission.

Cohort studies of soldiers garrisoned in the Kathmandu Valley suggest that fewer than 5\% of susceptible adults acquire serologically detectable HEV infection in a typical year (Shrestha and Scott, unpublished). These infection rates are consistent with the $40 \%$ antibody prevalence observed for adults in Kathmandu (D. W. Vaughn, D. W. unpublished data). The antibody prevalence observed among shorter-lived Rattus and
Bandicota animals suggests that these rodents sustain higher $\mathrm{HEV}$ infection rates than humans. Moreover, both species live in close contact with humans. If these species shed infective $\mathrm{HEV}$, they have the means and opportunity to serve as an important source of virus that causes human disease.

In conclusion, this study furnishes the first unconditional evidence that HEV infects wild rodent species that have close contact with humans. We assert that the detection of rodent HEV from 1996 that is phylogenetically related to human HEV from the same locale, the high prevalence of antibodies to HEV among Rattus and Bandicota species, which are known to have close association with humans, the wide distribution of infected (seropositive) animals in urban centers across the Kathmandu Valley, and the trapping of infected animals weeks before the presumed onset of epidemic transmission among humans in 1996 all support the hypothesis that rodents serve as a potentially important reservoir for this virus that infects humans. Further studies are needed to explore this important aspect of HEV ecology; better control of human disease could result.

\section{ACKNOWLEDGMENTS}

This research was supported by the U.S. Army Medical Research and Materiel Command and GlaxoSmithKline Biologicals through a Cooperative Research and Development Agreement.

The opinions and assertions herein are not to be construed as official or as reflecting the view of the U.S. Army or Department of Defense.

We thank Eileen Kelly and Linda Huang for help with manuscript preparation.

\section{REFERENCES}

1. Arankalle, V. A., M. S. Chadha, S. A. Tsarev, S. U. Emerson, A. R. Risbud, K. Banerjee, and R. H. Purcell. 1994. Seroepidemiology of water-borne hepatitis in India and evidence for a third enterically-transmitted hepatitis agent. Proc. Natl. Acad. Sci. USA 91:3428-3432.

2. Arankalle, V. A., M. O. Favorov, M. S. Chadha, D. M. Phule, and K. Banerjee. 1993. Rhesus monkeys infected with hepatitis E virus (HEV) from the former USSR are immune to subsequent challenge with an Indian strain of HEV. Acta Virol. 37:515-518.

3. Arankalle, V. A., M. K. Goverdhan, and K. Banerjee. 1994. Antibodies against hepatitis E virus in Old World monkeys. J. Viral Hepat. 1:125-129.

4. Aye, T. T., T. Uchida, X. Z. Ma, F. Iida, T. Shikata, H. Zhuang, and K. M. Win. 1992. Complete nucleotide sequence of a hepatitis E virus isolated from the Xinjiang epidemic (1986-1988) of China. Nucleic Acids Res. 20:3512. 
5. Balayan, M. S., R. K. Usmanov, N. A. Zamiatina, D. I. Dzhumalieva, and F. R. Karas. 1990. Experimental hepatitis E in domestic piglets. J. Med Virol. 32:58-59.

6. Bi, S. L., M. A. Purdy, K. A. McCaustland, H. S. Margolis, and D. W. Bradley. 1993. The sequence of hepatitis E virus isolated directly from a single source during an outbreak in China. Virus Res. 28:233-247.

7. Bradley, D. W., K. Krawczynski, E. H. Cook, K. A. McCaustland, C. D. Humphrey, J. E. Spelbring, H. L. A. Myint, and J. E. Maynard. 1987. Enterically transmitted non-A, non-B hepatitis: serial passage of disease in cynomolgus macaques and tamarins and recovery of disease-associated 27 to 34-nm viruslike particles. Proc. Natl. Acad. Sci. USA 84:6277-6281.

8. Carleton, M. D., and G. G. Musser. 1984. Murid rodents, p. 289-379. In S. Anderson and J. K. Jones, Jr. (ed.), Orders and families of recent mammals of the world. Wiley, New York, N.Y.

9. Clayson, E. T., B. L. Innis, K. S. Myint, S. Naraputi, D. W. Vaughn, S. Giri, P. Ranabhat, and M. P. Shrestha. 1995. Detection of hepatitis E virus infection among domestic swine in the Kathmandu Valley of Nepal. Am. J. Trop. Med. Hyg. 53:228-232.

10. Clayson, E. T., R. Snitbhan, and M. Ngarmpochana. 1996. Evidence that hepatitis $\mathrm{E}$ virus (HEV) is a zoonotic virus: detection of natural infection among swine, rats and chickens in an area endemic for human disease, $p$. 329-335. In Y. Busson, P. Coursaget, and M. Kane (ed.), Enterically transmitted hepatitis viruses. La Simarre, Joue-les-Tours, France.

11. Clayson, E. T., K. S. A. Myint, R. Snitbhan, D. W. Vaughn, and B. L. Innis. 1995. Viremia, fecal shedding, and immunoglobulin $M$ and $G$ responses in hepatitis E. J. Infect. Dis. 172:927-933.

12. De Groen, P. C. 1997. Hepatitis E in the United States: a case of 'hog fever'? Mayo Clin. Proc. 72:1197-1198.

13. Erker, J. C., S. M. Desal, G. G. Schlauder, G. J. Dawson, and I. K. Mushahwar. 1999. A hepatitis E virus variant from the United States: molecular characterization and transmission in cynomolgus macaques. J. Gen. Virol 80:681-690.

14. Gouvea, V., N. Snellings, S. J. Cohen, R. L. Warren, K. S. A. Myint, M. P. Shrestha, D. W. Vaughn, C. H. Hoke, and B. L. Innis. 1997. Hepatitis E virus in Nepal: similarities with the Burmese and Indian variants. Virus Res. 52:87-96.

15. He, J., C. G. Hayes, L. N. Binn, J. Seriwatana, D. W. Vaughn, R. A. Kuschner, and B. L. Innis. 2001. Hepatitis E virus DNA vaccine elicits immunologic memory in mice. J. Biomed. Sci. 8:223-226.

16. He, J., L. N. Binn, J. D. Caudill, L. V. Asher, C. F. Longer, and B. L. Innis 1999. Antiserum generated by DNA vaccine binds to hepatitis E virus (HEV) as determined by PCR and immune electron microscopy (IEM): application for HEV detection by affinity-capture RT-PCR. Virus Res. 62:59-65.

17. He, J., L. N. Binn, S. A. Tsarev, C. C. Hayes, J. A. Frean, M. Isaacson, and B. L. Innis. 2000. Molecular characterization of a hepatitis E virus isolate from Namibia. J. Biomed. Sci. 7:334-338.

18. Hsieh, S. Y., P. Y. Yang, Y. P. Ho, C. M. Chu, and Y. F. Liaw. 1998 Identification of a novel strain of hepatitis $\mathrm{E}$ virus responsible for sporadic acute hepatitis in Taiwan. J. Med. Virol. 55:300-304.

19. Huang, C. C., D. Nguyen, J. Fernandez, K. Y. Yun, K. E. Fry, D. W. Bradley, A. W. Tam, and G. R. Reyes. 1992. Molecular cloning and sequencing of the Mexico isolate of hepatitis E virus (HEV). Virology 191:550-558.

20. Kabrane-Lazizi, Y., K. L., J. B. Fine, J. E. Elm, G. E. Glass, H. Higa, A Diwan, C. J. Gibbs, X. J. Meng, S. U. Emerson, and R. H. Purcell. 1999 Evidence for widespread infection of wild rats with hepatitis $\mathrm{E}$ virus in the United States. Am. J. Trop. Med. Hyg. 61:331-335.

21. Karetnyi, Y. V., D. I. Dzhumalieva, R. K. Usmanov, I. P. Titova, Y. A. Lituak, and M. S. Balayan. 1993. Possible involvement of rodents in the spread of hepatitis E. J. Microbiol. Epidemiol. Immunol. 41:52-56. (In Russian.)

22. Kwo, P. Y., G. G. Schlauder, H. A. Carpenter, P. J. Murphy, E. Rosenblatt, G. J. Dawson, E. E. Mast, K. Krawczynski, and V. Balan. 1997. Acute hepatitis $\mathrm{E}$ by a new isolate acquired in the United States. Mayo Clin. Proc. 72:1133-1136

23. Maneerat, Y., E. T. Clayson, K. S. A. Myint, G. D. Young, and B. L. Innis. 1996. Experimental infection of laboratory rats with the hepatitis E virus. J. Med. Virol. 48:121-128.

24. McCrudden, R., S. O'Connell, T. Farrant, S. Beaton, J. P. Iredale, and D. Fine. 2000. Sporadic acute hepatitis E in the United Kingdom: an underdiagnosed phenomenon? Gut 46:732-733.

25. Meng, X. J., R. H. Purcell, P. G. Halbur, J. R. Lehman, D. M. Webb, T. S. Tsareva, J. S. Haynes, B. J. Thacker, and S. U. Emerson. 1997. A novel virus in swine is closely related to the human hepatitis E virus. Proc. Natl. Acad. Sci. USA 94:9860-9865.

26. Michael, O. F., M. Y. Kosoy, S. A. Tsarev, and J. E. Childs. 2000. Prevalence of antibody to hepatitis E virus among rodents in the United States. J. Infect. Dis. 181:449-455.

27. Panda, S. K., S. K. Nanda, M. Zafrullah, I. H. Ansari, M. H. Ozderner, and S. Jameel. 1955. An Indian strain of hepatitis E virus (HEV): cloning, sequence, and expression of structural region and antibody responses in ser from individuals from an area of high-level HEV endemicity. J. Clin. Microbiol. 33:2653-2659.

28. Purcell, R. H. 1996. Hepatitis E virus, p. 2831-2843. In B. N. Fields, D. M Knipe, and P. M. Howley (ed.), Fields virology, 3rd ed., vol. 2. LippincottRaven Publishers, Philadelphia, Pa.

29. Reyes, G. R. 1997. Overview of the epidemiology and biology of the hepatitis E virus, p. 239-258. In R. A. Willson (ed.), Viral hepatitis. Marcel Dekker, Inc., New York, N.Y.

30. Rizzetto, M., R. H. Purcell, J. L. Gerin, and G. Verme (ed.). 1997. Viral hepatitis and liver diseases, p. 313-316. Edizioni Minerva Medica, Turin, Italy.

31. Schlauder, G. G., G. J. Dawson, J. C. Erker, P. Y. Kwo, M. F. Knigge, D. L. Smalley, J. E. Rosenblatt, S. M. Desai, and I. K. Mushahwar. 1998. The sequence and phylogenetic analysis of a novel hepatitis E virus isolated from a patient with acute hepatitis reported in the Unites States. J. Gen. Virol. 79:447-456.

32. Schlauder, G. G., S. M. Desai, A. R. Zanetti, N. C. Tassopoulos, and I. K. Mushahwar. 1999. Novel hepatitis E virus (HEV) isolates from Europe: evidence for additional genotype of HEV. J. Med. Virol. 57:243-251.

33. Tsarev, S. A., L. N. Binn, P. T. Gomatos, R. R. Arthur, M. Monier, H. van Cuyck-Gandre, C. F. Longer, and B. L. Innis. 1999. Phylogenetic analysis of hepatitis E virus isolates from Egypt. J. Med. Virol. 57:68-74.

34. Tsarev, S. A., S. U. Emerson, G. R. Reyes, T. S. Tsareva, L. J. Legters, I. A. Malik, M. Iqbal, and R. H. Purcell. 1992. Characterization of a prototype strain of hepatitis E virus. Proc. Natl. Acad. Sci. USA 89:559-563.

35. Usmanov, R. K., M. S. Balayan, O. V. Dvoinikova, D. B. Alymbayeva, N. A. Zamyatina, Y. A. Kazachkov, and V. I. Belov. 1994. Experimental hepatitis E infection in lambs. Vopr. Virusol. 39:165-168.

36. Van Cuyck-Gandre, H. V., H. Y. Zhang, S. A. Tsarev, N. J. Clements, S. J. Cohen, J. D. Caudil, Y. Buission, P. Coursaget, R. L. Warren, and C. F. Longer. 1997. Characterization of hepatitis E virus (HEV) from Algeria and Chad by partial genome sequence. J. Med. Virol. 53:340-347.

37. Withers, M. R., M. T. Correa, M. Morrow, M. E. Stebbins, J. Seriwatana, W. D. Webster, M. B. Boak, and D. W. Vaughn. 2002. Antibody levels to hepatitis E virus in North Carolina swine workers, non-swine workers, swine, and murids. Am. J. Trop. Med. Hyg. 66:384-388.

38. Yin, S., R. H. Purcell, and S. U. Emerson. 1994. A new Chinese isolate of hepatitis E virus: comparison with strains recovered from different geographical regions. Virus Genes 9:23-32.

39. Zanetti, A. R., G. G. Schlauder, L. Romano, E. Tanzi, P. Fabris, G. J. Dawson, and K. Mushahwar. 1999. Identification of a novel variant of hepatitis E virus in Italy. J. Med. Virol. 57:356-369. 